Check for updates

Cite this: RSC Adv., 2018, 8, 5840

\title{
Core-shell microspheres for the ultrafast degradation of estrogen hormone at neutral $\mathrm{pH} \uparrow$
}

\begin{abstract}
Katherine Villa, (D) a Jemish Parmar, (iD) ${ }^{\text {ab }}$ Diana Vilela (D) ab and Samuel Sánchez (D) *abc
In the past few years there has been growing concern about human exposure to endocrine disrupting chemicals. This kind of pollutants can bioaccumulate in aquatic organisms and lead to serious health problems, especially affecting child development. Many efforts have been devoted to achieving the efficient removal of such refractory organics. In this regard, a novel catalyst based on the combination of $\alpha-\mathrm{FeOOH}$ and $\mathrm{MnO}_{2} \mathrm{QMnCO}_{3}$ catalysts has been developed by up-scalable techniques from cheap precursors and tested in the photo-Fenton-like degradation of an endocrine disruptor. Almost total degradation of $17 \alpha$-ethynylestradiol hormone was achieved after only 2 min of simulated solar irradiation at neutral $\mathrm{pH}$. The outstanding performance of $\mathrm{FeOOH}\left(\mathrm{MnO}_{2} \mathrm{aMnCO}_{3}\right.$ microspheres was mainly attributed to a larger generation of hydroxyl radicals, which are the primary mediators of the total oxidation for this hormone. This work contributes to the development of more cost-effective systems for the rapid and efficient removal of persistent organic pollutants present in sewage plant effluents under direct solar light.
\end{abstract}

Received 23rd October 2017 Accepted 28th January 2018

DOI: 10.1039/c7ra11705a

rsc.li/rsc-advances

the reaction between a dissolved iron salt $\left(\mathrm{Fe}^{2+}\right)$ and hydrogen peroxide $\left(\mathrm{H}_{2} \mathrm{O}_{2}\right)$, which can degrade all the organic molecules to $\mathrm{CO}_{2}$ and water. The performance of Fenton reaction can be improved by the so-called photo-Fenton degradation, where UV-visible light is used to generate extra reactive radicals from the photolysis of $\mathrm{H}_{2} \mathrm{O}_{2}$, and enhance the regeneration of the $\mathrm{Fe}^{2+}$ catalyst. ${ }^{6,7}$ Thus, the possibility of using solar light as energy source is an attractive way to transform it in a sustainable and more efficient technology.

Nevertheless, a real application of this advanced oxidation process is still hampered, mainly by the intrinsic limitations of the Fenton catalysts related to the requirement of an acidic $\mathrm{pH}$. This entails extra costs associated with neutralization steps and further recovery of the formed iron sludges.

To address these problems, extensive recent research has focused on the development of heterogeneous iron-based catalysts that can activate $\mathrm{H}_{2} \mathrm{O}_{2}$ at neutral $\mathrm{pH}$ and facilitate recovery after the treatment process. ${ }^{8-12}$ However, the efficiency of these heterogeneous Fenton-like catalysts is usually found to be lower than its homogeneous counterpart. Thus, the design of heterogeneous catalysts that can effectively harvest solar light and decompose $\mathrm{H}_{2} \mathrm{O}_{2}$ into $\mathrm{HO}^{\circ}$ without the need for a $\mathrm{pH}$ change is crucial for the practical application of solar Fentonbased wastewater treatments.

Among the catalysts reported for heterogeneous photoFenton-like reaction, amorphous iron oxide $\mathrm{FeOOH}$ ( $\alpha$-goethite) has shown an outstanding performance, even though its applicability has been limited by the slow $\mathrm{Fe}^{3+} / \mathrm{Fe}^{2+}$ cycle rates. ${ }^{\mathbf{1 3 - 1 5}}$ Alternatively, other transition metal oxides, such as $\mathrm{CeO}_{2}, \mathrm{CuO}$ and $\mathrm{MnO}_{2}$, have also been reported as active 
materials for Fenton-like oxidation treatments. ${ }^{\mathbf{1 6 - 1 8}}$ Among them, $\mathrm{MnO}_{2}$ (a non-toxic and cheap material) has not been extensively studied for the oxidation reaction of organic pollutants, despite being an efficient catalyst for the decomposition of $\mathrm{H}_{2} \mathrm{O}_{2} \cdot{ }^{19,20}$

Here, we investigate for the first time the photo-Fenton-like degradation of $17 \alpha$-ethynylestradiol hormone (EE2) using $\mathrm{FeOOH} @ \mathrm{MnO}_{2} @ \mathrm{MnCO}_{3}$ core-shell catalyst. This material was synthesized by a facile surface oxidation of spherical $\mathrm{MnCO}_{3}$ crystal template to $\mathrm{MnO}_{2} @ \mathrm{MnCO}_{3}$ and subsequent coating of $\alpha$-FeOOH nanoparticles on it. Since $\mathrm{MnO}_{2}$ facilitates the fast decomposition of $\mathrm{H}_{2} \mathrm{O}_{2}$ and iron cycling, the combination of $\alpha-\mathrm{FeOOH}$ and $\mathrm{MnO}_{2}$ results in a great enhancement of the overall catalytic process. Additionally, the performance of this material can be improved by using mainly visible light, which is the major component of the solar radiation. The outcome of this research would contribute to the feasibility of the photoFenton-like technology by using Fe/Mn microspheres-based system for the treatment of contaminated water with industrial pollutants.

\section{Experimental}

\section{Catalyst preparation}

$\mathrm{MnCO}_{3}$ microparticles were synthesized by mixing $70 \mathrm{~mL}$ of $0.014 \mathrm{M} \mathrm{MnSO}_{4}$ solution (ACS reagent $\geq 99.0 \%$, Sigma-Aldrich) with $0.79 \mathrm{~g}$ of $\mathrm{NH}_{4} \mathrm{CO}_{3}$ (Bioultra $\geq 99.5 \%$, Sigma-Aldrich) at room temperature for $15 \mathrm{~h} .{ }^{21}$ A schematic illustration of the synthesis procedure of $\alpha-\mathrm{FeOOH} @ \mathrm{MnO}_{2} @ \mathrm{MnCO}_{3}$ microspheres is shown in Fig. 1. A core-shell structure of $\mathrm{MnO}_{2}$ @$\mathrm{MnCO}_{3}$ was prepared by mixing $0.09 \mathrm{~g}$ of the as-synthesized $\mathrm{MnCO}_{3}$ with $6.0 \mathrm{~mL}$ of aqueous solution of $0.032 \mathrm{M} \mathrm{KMnO}_{4}$ (ACS reagent $\geq 99.0 \%$, Sigma-Aldrich) for $4 \mathrm{~h}$. The sample was collected by centrifugation and washed with Milli-Q water. Afterwards, the $\mathrm{MnO}_{2} @ \mathrm{MnCO}_{3}$ sample was dispersed in $30 \mathrm{~mL}$ of glycerol-water mixture by sonication for $20 \mathrm{~min}$. FeOOH was grown on the $\mathrm{MnO}_{2} @ \mathrm{MnCO}_{3}$ microparticles by adding $0.166 \mathrm{~g}$ of $\mathrm{FeSO}_{4} \cdot 7 \mathrm{H}_{2} \mathrm{O}$ (ACS reagent $\geq 99.0 \%$, Sigma-Aldrich) to that mixture and stirring for $10 \mathrm{~min}$. Afterwards, the black resulting suspension was transferred into a $50 \mathrm{~mL}$ Teflon-lined stainlesssteel autoclave and heated at $120^{\circ} \mathrm{C}$ for $24 \mathrm{~h}$. The dark orange precipitate was collected by centrifugation and washed sequentially with water and ethanol, and dried at $60^{\circ} \mathrm{C}$ for $6 \mathrm{~h}$. A control synthesis experiment was carried out by adding the iron precursor (in the absence of $\mathrm{MnO}_{2} @ \mathrm{MnCO}_{3}$ microparticles) to confirm that the iron oxide phase grown by the hydrothermal reaction consists of $\alpha$-FeOOH.

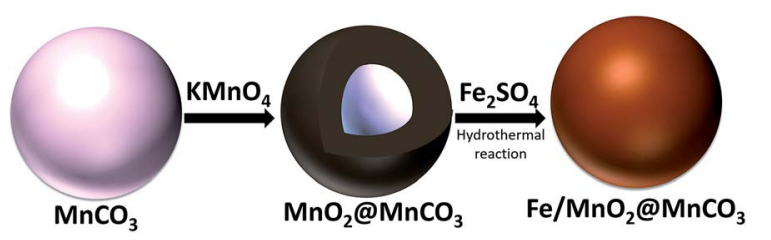

Fig. 1 Schematic illustration of the synthesis procedure of $\mathrm{Fe} / \mathrm{MnO}_{2} \mathrm{aMnCO}_{3}$ catalyst.
For the sake of simplicity, the $\mathrm{FeOOH} @ \mathrm{MnO}_{2} @ \mathrm{MnCO}_{3}$ material has been labeled as $\mathrm{Fe} / \mathrm{MnO}_{2} @ \mathrm{MnCO}_{3}$.

\section{Catalyst characterization}

The crystal structure of the as-synthesized samples was determined by X-ray powder diffraction (XRD) using a Bruker D8 Advance diffractometer equipped with a $\mathrm{Cu} \mathrm{K} \alpha$ radiation (1.5417 ̊) source, a LYNXEYE super speed detector and a Ni filter. X-ray diffraction data was collected in the $2 \theta$ range between $20^{\circ}$ and $80^{\circ}$ using a scan rate of $0.05^{\circ}$ by $2 \mathrm{~s}$. The light absorption properties were measured by using a UV-Vis diffuse reflectance spectrophotometer (Perkin Elmer Lambda 950 UV-Vis) with a wavelength range of $250-800 \mathrm{~nm}$. A Zeiss Auriga microscope equipped with energy-dispersive X-ray (EDX) detector was used to perform scanning electron microscopy (SEM) and EDX analysis.

X-ray photoelectron spectroscopy (XPS) from SPECS system (Germany) was used to identify Mn and Fe oxidation states on the samples. The instrument was equipped with XR50 duel anode source (Al operated at $150 \mathrm{~W}$ ) and a Phoibos MCD-9 detector. All measurements were done under the vacuum (pressure $5 \times 10^{-9} \mathrm{mbar}$ ) and the hemispherical analyzer was set at the pass energy $25 \mathrm{eV}$ while the high resolution spectra step size was set at $0.1 \mathrm{eV}$. Casa XPS program (Casa Software Ltd., UK) was used for the data analysis.

\section{Photo-Fenton set-up}

The degradation of an aqueous solution of EE2 was carried out in a $10 \mathrm{~mL}$ capacity cylindrical glass vessel. The catalyst slurries were magnetically stirred during the reaction. For the photoFenton-like experiments, a $300 \mathrm{~W}$ high pressure UV-visible lamp (Ultravitalux Osram, 280-780 nm) was used to simulate solar irradiation. In a typical experiment, $6 \mathrm{~mL}$ of the $0.5 \mathrm{ppm}$ of EE2 solution containing $0.0015 \mathrm{~g}$ of catalyst was placed in the reactor. Since the main aim of this study was to evaluate the catalytic activity at near-neutral $\mathrm{pH}$ (6.7), no acidic or basic $\mathrm{pH}$ adjustment was performed.

Prior to illumination, the suspension was sonicated in the dark for $30 \mathrm{~min}$ to reach adsorption-desorption equilibrium. After that, the lamp was turned on and $\mathrm{H}_{2} \mathrm{O}_{2}$ was added to initiate the reaction. Liquid samples were periodically taken out, immediately centrifuged, and then analyzed by high performance liquid chromatography (Acquity) coupled to a triple quadrupole mass spectrometer LC/MS/MS (API 3000). The mobile phase consisted of $50: 50 \mathrm{v} / \mathrm{v}$ ultrapure water : acetonitrile mixture and the injection volume of the sample was $10 \mu \mathrm{L}$. In the case of the MB degradation, the concentration was monitored by measuring its absorbance at $664 \mathrm{~nm}\left(\lambda_{\max }\right)$ during the reaction by using a UV-Vis spectrophotometer (Specord 50 Plus).

A blank test without catalyst (only $\mathrm{H}_{2} \mathrm{O}_{2}+$ light irradiation) was also performed to evaluate the contribution of the photolysis of $\mathrm{H}_{2} \mathrm{O}_{2}$, which involves the generation of hydroxyl radicals, on the oxidation of our target molecule (EE2). Additionally, a test with catalyst under light irradiation and no $\mathrm{H}_{2} \mathrm{O}_{2}$ was carried out to estimate the photocatalytic influence on the resulting performance. 
The hydroxyl radical generation during the photo-Fenton-like reaction was identified by following a fluorescence method, using $5 \times 10^{-4} \mathrm{M}$ terephthalic acid (TA) as a chemical trap of HO'. The excitation wavelength was $320 \mathrm{~nm}$ and the fluorescence emission spectra were acquired from $350-600 \mathrm{~nm}$ using a multimode microplate reader (Infinite M200 PRO). The experimental conditions were the same as those described above for the irradiation tests and $\mathrm{H}_{2} \mathrm{O}_{2}$ concentration was $0.1 \mathrm{M}$.

\section{Results and discussion}

To study the composition and structure of the catalysts, different characterization techniques such as XRD, UV-Vis and
SEM/EDX were used (Fig. 2). As observed in XRD patterns displayed in Fig. 2a, $\mathrm{MnO}_{2} @ \mathrm{MnCO}_{3}$ only presents diffraction peaks corresponding to the crystalline structure of $\mathrm{MnCO}_{3}$ (JCPDS no. 044-1472). Since the intensity of the core peaks was too high, the external shell of $\mathrm{MnO}_{2}$ was not appreciated, which is in agreement with previously reported works. ${ }^{20,21}$ The XRD patterns of the iron oxide obtained by the hydrothermal reaction indicate the formation of $\alpha$-goethite $\mathrm{FeOOH}$ phase (JCPDS no. 029-0713). In the case of $\mathrm{Fe} / \mathrm{MnO}_{2} @ \mathrm{MnCO}_{3}$ microparticles, the diffraction peaks are very similar to those of bare $\mathrm{MnO}_{2} @-$ $\mathrm{MnCO}_{3}$, being also difficult to detect the peaks associated with $\mathrm{MnO}_{2}$. However, an additional peak at around $20.1^{\circ}$ and a shoulder at approximately $62.1^{\circ}$ can be attributed to the a)

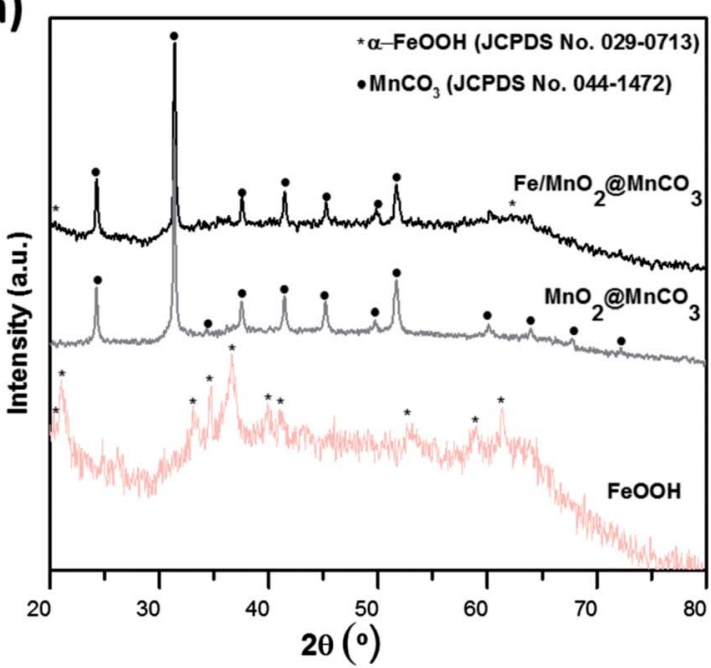

b)

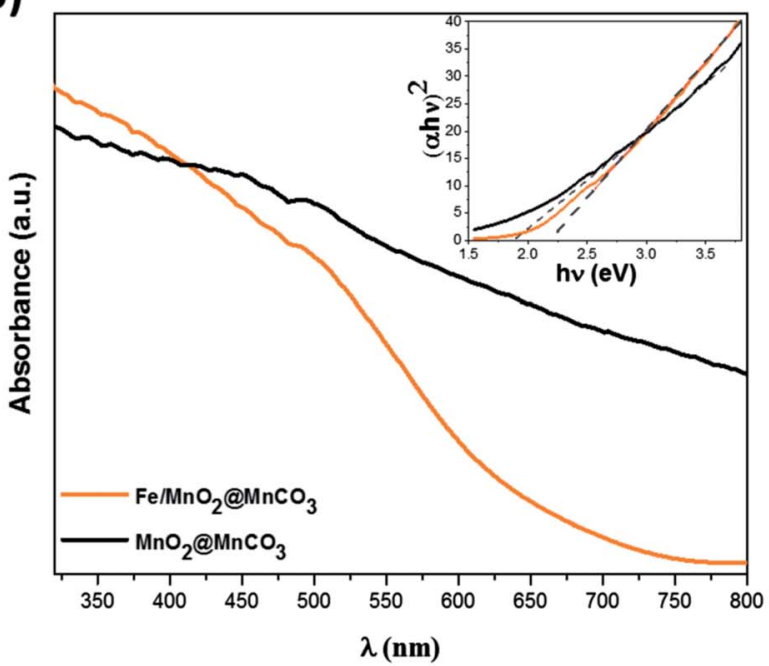

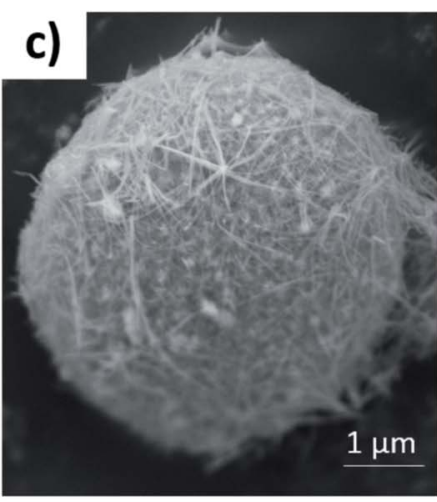
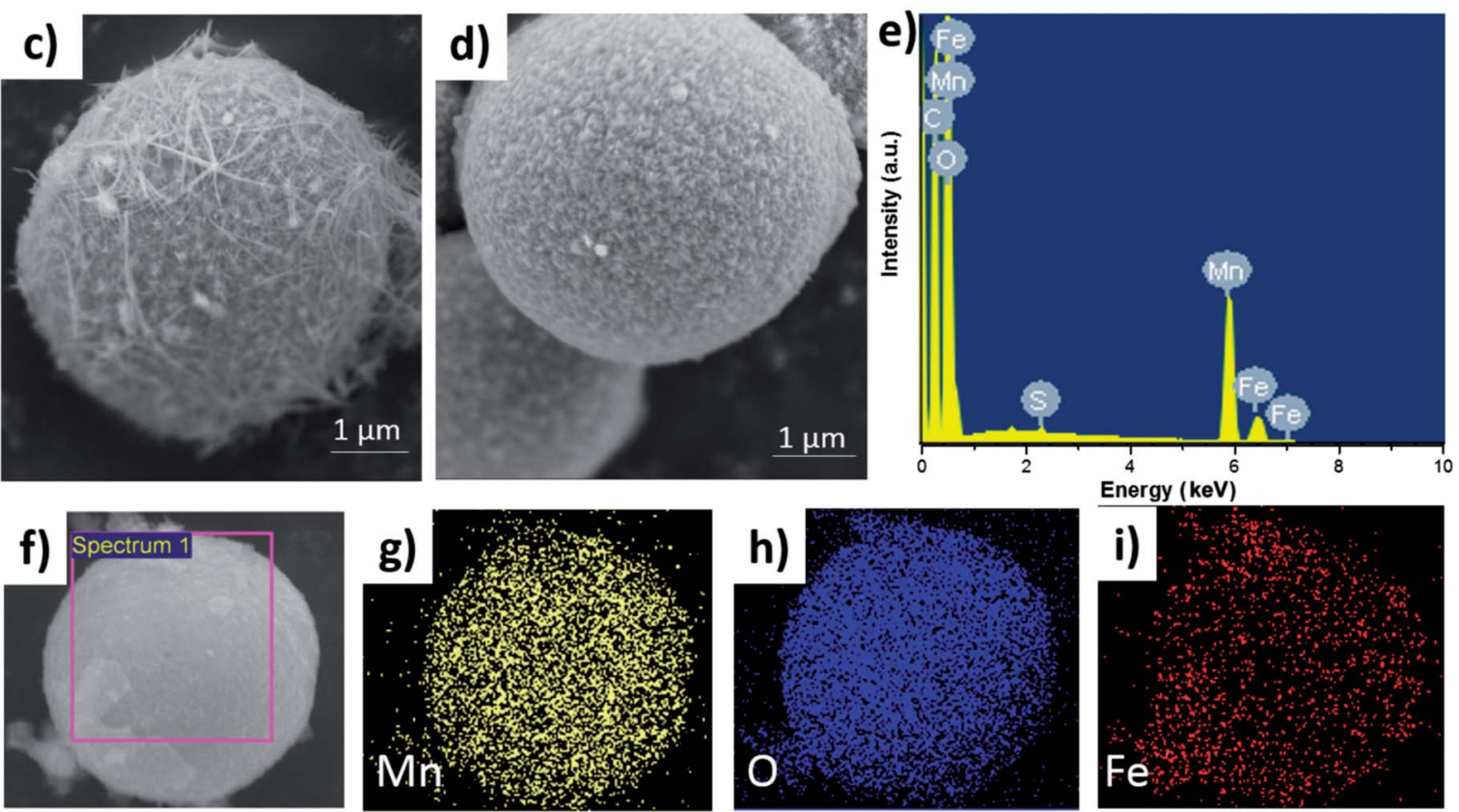

Fig. 2 Characterization of materials. (a) X-ray powder diffraction patterns of $\alpha$-FeOOH, $\mathrm{MnO}_{2} \mathrm{aMnCO}_{3}$ and Fe/MnO $2 @ \mathrm{MnCO}_{3}$, (b) UV-Vis diffuse reflectance spectra (DRS) of $\mathrm{MnO}_{2}\left(\mathrm{aMnCO}_{3}\right.$ and $\mathrm{Fe} / \mathrm{MnO}_{2}\left(\mathrm{aMnCO}_{3}\right.$. In the inset, the Tauc plot of (absorbance energy) ${ }^{2}$ against energy obtained from DRS UV-Vis spectra, (c) SEM image of $\mathrm{MnO}_{2} @ \mathrm{MnCO}_{3}$, (d) SEM image of Fe/MnO${ }_{2} \mathrm{aMnCO}_{3}$, (e) EDX spectra of Fe/MnO $\mathrm{MnCO}_{3}$, (f-i) EDX mapping of $\mathrm{Fe} / \mathrm{MnO}_{2}\left(\mathrm{MnCO}_{3}\right.$. 
$\alpha-\mathrm{FeOOH}$ phase from the surface of $\mathrm{Fe} / \mathrm{MnO}_{2} @ \mathrm{MnCO}_{3}$ microspheres.

A slight shift in the optical absorption of bare $\mathrm{MnO}_{2}$ @$\mathrm{MnCO}_{3}$ catalyst was observed in the UV-Vis diffuse reflectance spectra after being loaded with $\alpha$-FeOOH (Fig. 2b). The band gap energy $\left(E_{\mathrm{g}}\right)$ of the materials was calculated from the absorption data by using the Tauc plots (see inset, Fig. 2b), where (absorbance energy) ${ }^{2}$ is plotted against energy. ${ }^{22}$ The estimated values of 1.9 and $2.2 \mathrm{eV}$ for $\mathrm{MnO}_{2} @ \mathrm{MnCO}_{3}$ and $\mathrm{Fe} / \mathrm{MnO}_{2} @ \mathrm{MnCO}_{3}$ catalysts, respectively, confirm that the optical absorption properties of these Mn-based materials lie in the visible region. Considering a real application under direct solar light, this is advantageous in comparison with other widely studied materials such as $\mathrm{TiO}_{2}$, which can only be activated by ultraviolet light. ${ }^{23,24}$

SEM images are shown in Fig. 2c and d. $\mathrm{MnO}_{2} @ \mathrm{MnCO}_{3}$ microparticles consist of a spherical shape with an approximate diameter of $4.5 \mu \mathrm{m}$ and a fibrous surface. It is worth noting that due to their large size compared to nanometric particles, these microparticles can be easily recovered from the solution after each catalytic reaction. In the case of the $\mathrm{Fe} / \mathrm{MnO}_{2} @ \mathrm{MnCO}_{3}$, the spherical shape, size, and roughness were preserved (Fig. 2d). However, due to the formation of the external $\alpha$-FeOOH coating on the surface, it presents a higher homogeneity than $\mathrm{MnO}_{2} @ \mathrm{MnCO}_{3}$. The EDX spectrum confirmed the presence of $\mathrm{Fe}$ in the $\mathrm{Fe} / \mathrm{MnO}_{2} @ \mathrm{MnCO}_{3}$ catalyst structure (Fig. 2e), in agreement with XRD characterization. Furthermore, EDXmapping showed the uniform distribution of $\mathrm{Fe}$ on the catalyst surface (Fig. 2f-i).

The chemical states of $\mathrm{Fe}$ and $\mathrm{Mn}$ in $\mathrm{Fe} / \mathrm{MnO}_{2} @ \mathrm{MnCO}_{3}$ sample were investigated by XPS. Fig. 3a shows the XPS spectrum of Fe 2p. The complex multiplet-split of Fe $2 \mathrm{p}$ regions is typical of $\mathrm{Fe}^{3+}$ compounds. ${ }^{25}$ The two main peaks at 712.75 and $726.14 \mathrm{eV}$ can be assigned to $\mathrm{Fe} 2 \mathrm{p}_{3 / 2}$ and $\mathrm{Fe} 2 \mathrm{p}_{1 / 2}$ signals from $\mathrm{FeOOH}$. Additionally, the satellite peak of $\mathrm{Fe} 2 \mathrm{p}_{3 / 2}$ at $720.83 \mathrm{eV}$ would confirm the presence of $\mathrm{Fe}^{3+}$ ions in the composite. ${ }^{26,27} \mathrm{In}$ the case of Mn 2p (Fig. 3b), two main peaks at 643.73 and $655.55 \mathrm{eV}$ are distinguished, corresponding to $\mathrm{Mn} 2 \mathrm{p}_{3 / 2}$ and $\mathrm{Mn}$ $2 \mathrm{p}_{1 / 2}$, respectively. These two spin-orbit components have a separation of approximately $12 \mathrm{eV}$, evidencing the presence of $\mathrm{Mn}^{4+}$ from the $\mathrm{MnO}_{2}$ material. ${ }^{26} \mathrm{An}$ additional $\mathrm{Mn} 2 \mathrm{p}_{3 / 2}$ satellite peak at $648.19 \mathrm{eV}$ can be attributed to the presence of $\mathrm{MnO}$ (MnOOH oxide), ${ }^{25}$ resulting from the hydrothermal treatment in the presence of $\mathrm{FeOOH}$ precursors. This fact evidences a mixture of valence states $\left(\mathrm{Mn}^{3+}\right.$ and $\left.\mathrm{Mn}^{4+}\right)$ in the $\mathrm{Fe} /$ $\mathrm{MnO}_{2} @ \mathrm{MnCO}_{3}$ catalyst. The XPS O 1s region shows three contributions at 530.12, 531.93 and $533.70 \mathrm{eV}$ (Fig. 3c). The first one can be attributed to the oxygen atoms in the lattice of metal-oxygen structure. The second one at $531.93 \mathrm{eV}$ corresponds to the metal-hydroxyl bond and the latter at $533.70 \mathrm{eV}$ is assigned to the water adsorbed on the catalyst surface. ${ }^{28-30}$ Finally, the spectrum from C 1s display a high signal observed at $291.8 \mathrm{eV}$ (Fig. 3d) may be assigned to the carbonate groups $\left(\mathrm{CO}_{3}{ }^{2-}\right)$ present in the sample, due to the composite core $\left(\mathrm{MnCO}_{3}\right)$.

A preliminary screening of the bare catalysts and the composite was carried out at neutral $\mathrm{pH}$ using methylene blue (a common dye waste). As presented in Fig. S1, $\dagger$ the performance of $\mathrm{FeOOH}$ catalyst is almost negligible, whereas $\mathrm{Fe} /$ $\mathrm{MnO}_{2} @ \mathrm{MnCO}_{3}$ composite shows a remarkable Fenton-like activity compared to $\mathrm{MnO}_{2} @ \mathrm{MnCO}_{3}$ material. Based on this, FeOOH photocatalyst was not considered for further degradation experiments.

The photo-Fenton-like degradation of EE2, as an example of a persistent endocrine disrupting pollutant, was studied in an aqueous suspension containing the as-synthesized $\mathrm{MnO}_{2}$ @$\mathrm{MnCO}_{3}$ and $\mathrm{Fe} / \mathrm{MnO}_{2} @ \mathrm{MnCO}_{3}$ catalysts in the presence of $\mathrm{H}_{2} \mathrm{O}_{2}$, under UV-visible light irradiation. Considering that endocrine disrupting chemicals are usually found at low concentrations in sewage plant effluents, and taking into account that even at those low levels they are toxic, ${ }^{31,32}$ we selected a $0.5 \mathrm{ppm}$ EE2 concentration for the degradation tests.

Initially, the concentration of $\mathrm{H}_{2} \mathrm{O}_{2}$ was optimized. As shown in Fig. 4a, the degradation of 0.5 ppm EE2 enhanced from 10 to $90 \%$ by increasing the $\mathrm{H}_{2} \mathrm{O}_{2}$ concentration from $0.05 \mathrm{M}$ to $0.1 \mathrm{M}$. However, a further increase to $0.2 \mathrm{M}$ did not lead to an additional improvement of the degradation rates, evidencing that a plateau was reached. Therefore, $0.1 \mathrm{M} \mathrm{H}_{2} \mathrm{O}_{2}$ was selected as the optimal minimum concentration for further experiments. Afterwards, to select the optimal amount of catalyst, different catalyst loadings from 0.25 to $1 \mathrm{~g} \mathrm{~L}^{-1}$ were tested (Fig. 4b). The highest degradation value was obtained by using the lowest amount of catalyst $\left(0.25 \mathrm{~g} \mathrm{~L}^{-1}\right)$. This fact can be attributed to the severe light scattering effect provoked by larger catalyst concentrations, which reduces the number of available photons able to reach each catalyst particle, ${ }^{33,34}$ resulting in a decrease of the radical species generation and a subsequent decrease in the degradation efficiency of the EE2 hormone.

Fig. $4 \mathrm{c}$ and $\mathrm{d}$ show the degradation kinetics of $0.5 \mathrm{ppm}$ EE2 compound after $10 \mathrm{~min}$ of UV-visible irradiation. Control experiments consisting of the irradiation of $\mathrm{Fe} / \mathrm{MnO}_{2} @ \mathrm{MnCO}_{3}$ (without $\mathrm{H}_{2} \mathrm{O}_{2}$ ) and $0.1 \mathrm{M} \mathrm{H}_{2} \mathrm{O}_{2}$ (without catalyst) were carried out under the optimized reaction conditions. It was found that the photocatalytic activity of $\mathrm{Fe} / \mathrm{MnO}_{2} @ \mathrm{MnCO}_{3}$ without $\mathrm{H}_{2} \mathrm{O}_{2}$ only contributed to around $6 \%$ of the degradation after $10 \mathrm{~min}$. Furthermore, it is well-known that the irradiation of $\mathrm{H}_{2} \mathrm{O}_{2}$ with UV-visible irradiation also leads to hydroxyl radicals generation by photolysis. $^{35}$ Nonetheless, under those conditions the degradation yield was also low and slow. It is worth highlighting that the high pressure lamp used in this work (maximum intensity at $365 \mathrm{~nm}$ ) cannot lead to the photodegradation of the synthetic hormone. ${ }^{36}$ When the photo-Fenton tests were performed in the presence of $\mathrm{MnO}_{2} @ \mathrm{MnCO}_{3}$ and $\mathrm{Fe} / \mathrm{MnO}_{2} @$ $\mathrm{MnCO}_{3}$ catalysts and $0.1 \mathrm{M} \mathrm{H}_{2} \mathrm{O}_{2}$, the degradation rates were noticeably enhanced after only two minutes of light irradiation. This result shows that the presence of the catalyst is required to improve the decomposition of $\mathrm{H}_{2} \mathrm{O}_{2}$ and accelerate the degradation rate.

The $\mathrm{MnO}_{2} @ \mathrm{MnCO}_{3}$ catalyst showed a 62\% EE2 degradation within $2 \mathrm{~min}$ of the photo-Fenton-like reaction, and that maximum degradation yield remained constant over time, suggesting that the catalyst is rapidly consuming all the $\mathrm{H}_{2} \mathrm{O}_{2}$ to generate $\mathrm{O}_{2}$. Moreover, unlike the Fe-based catalysts, $\mathrm{MnO}_{2}$ is more prone to generate superoxide and hydroperoxy radicals, ${ }^{37}$ 

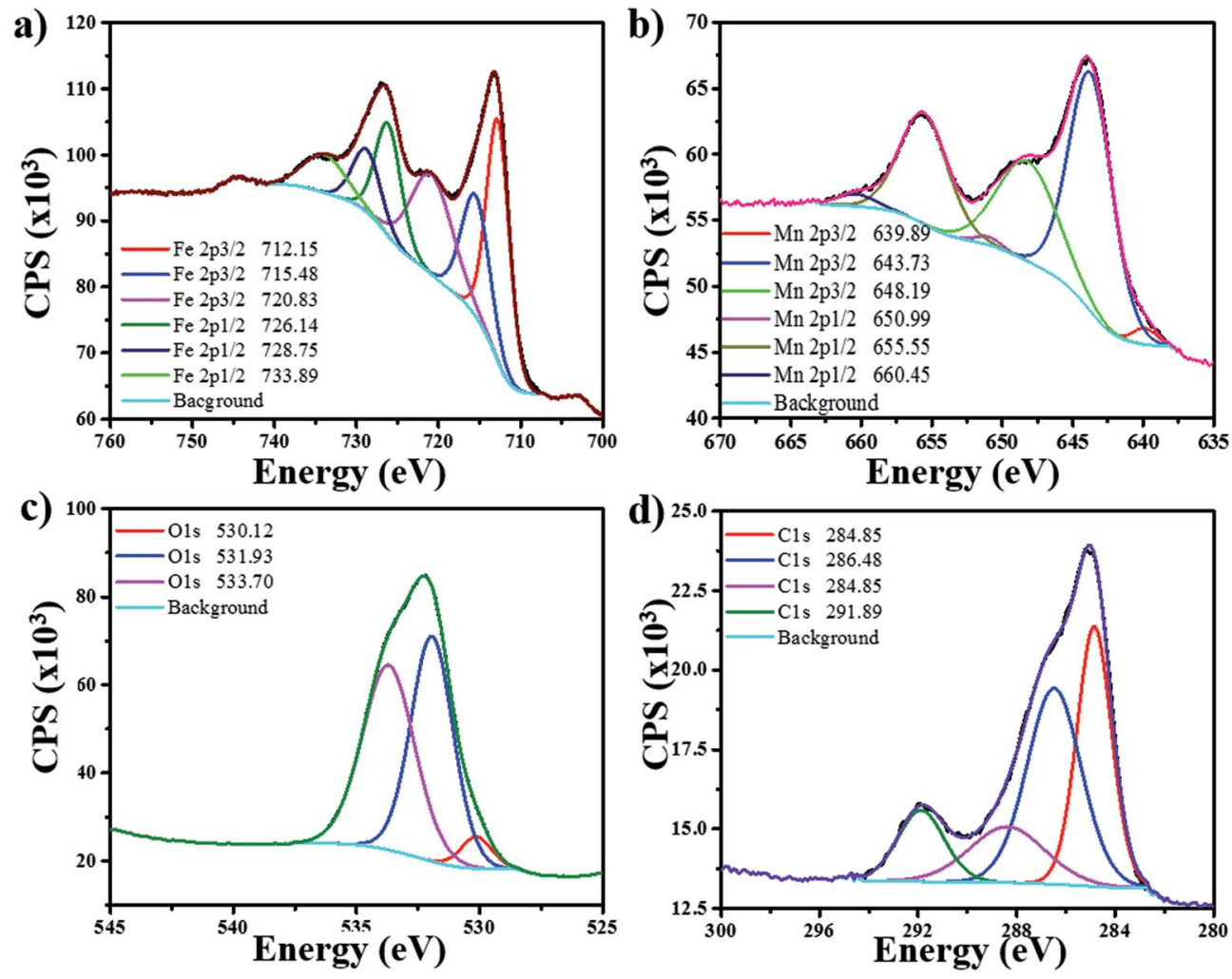

Fig. 3 XPS spectra of $\mathrm{Fe} / \mathrm{MnO}_{2} \mathrm{aMnCO}_{3}$ catalyst for its different elements: (a) iron (Fe), (b) manganese (Mn), (c) oxygen (O), (d) carbon (C).
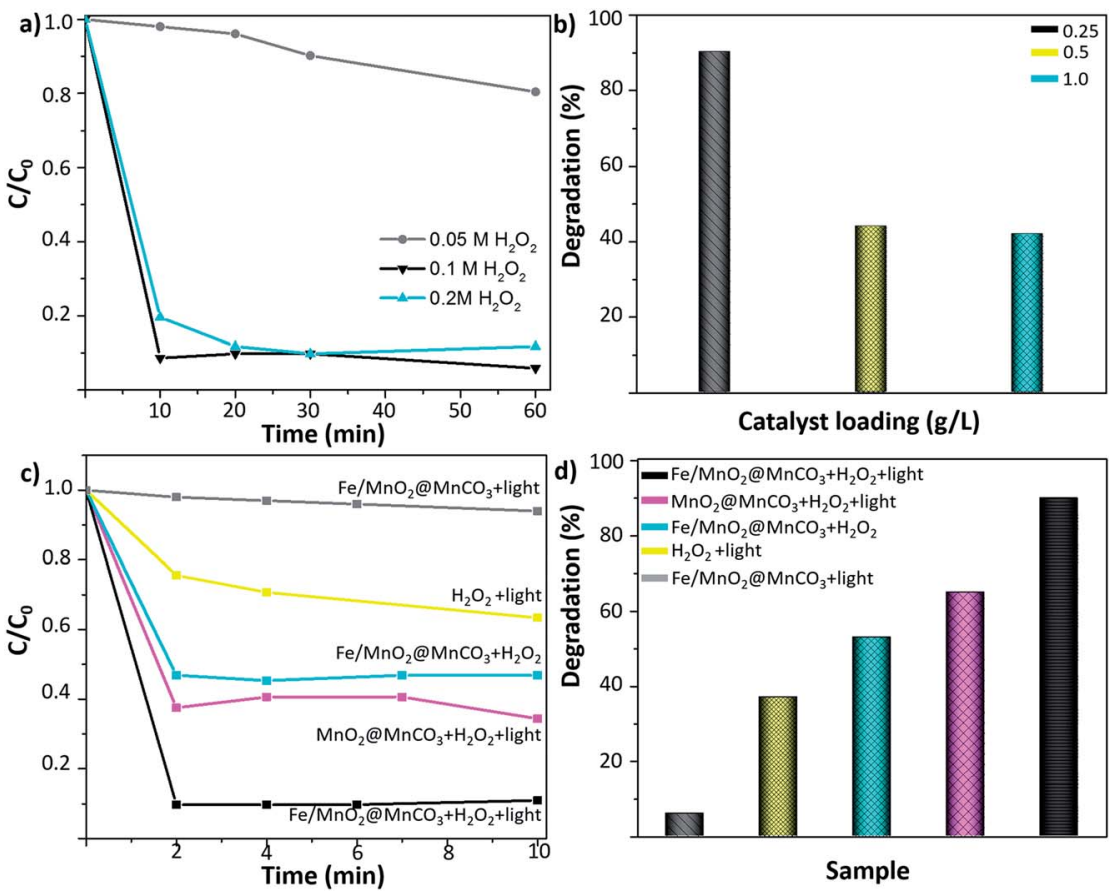

Fig. 4 Photo-Fenton-like degradation of $17 \alpha$-ethynylestradiol. (a) Effect of $\mathrm{H}_{2} \mathrm{O}_{2}$ concentration $\left(0.25 \mathrm{~g} \mathrm{~L}^{-1}\right.$ catalyst loading) and (b) effect of catalyst loading $\left(0.1 \mathrm{M} \mathrm{H}_{2} \mathrm{O}_{2}\right)$, (c) $\mathrm{C} / \mathrm{C}_{0}$ kinetics and (d) photo-Fenton-like degradation of $17 \alpha$-ethynylestradiol after 10 min of reaction under different conditions: Fe/ $\mathrm{MnO}_{2} \mathrm{aMnCO}_{3}+$ light, $\mathrm{H}_{2} \mathrm{O}_{2}+$ light, $\mathrm{Fe} / \mathrm{MnO}_{2} @ \mathrm{MnCO}_{3}+\mathrm{H}_{2} \mathrm{O}_{2}$ (in the dark), $\mathrm{MnO}_{2} @ \mathrm{MnCO}_{3}+\mathrm{H}_{2} \mathrm{O}_{2}+$ light, and Fe/ $\mathrm{MnO}_{2} \mathrm{aMnCO}_{3}+\mathrm{H}_{2} \mathrm{O}_{2}+$ light. 
which have a lower oxidation potential than the hydroxyl radicals. ${ }^{38}$

As shown in Fig. 4d, the highest degradation yield was achieved with the $\mathrm{Fe} / \mathrm{MnO}_{2} @ \mathrm{MnCO}_{3}$ microspheres. This improvement in the photo-Fenton performance might be explained by multiple factors, such as the synergistic effect arising from the activity of manganese and iron metal oxides in the photoFenton-like reaction. In addition, it has been reported that Febased catalysts are not efficient in activating $\mathrm{H}_{2} \mathrm{O}_{2}$ at high pH values, ${ }^{39-42}$ while $\mathrm{MnO}_{2}$ is able to efficiently decompose $\mathrm{H}_{2} \mathrm{O}_{2}$ molecules even at neutral $\mathrm{pH}^{37}$ Due to this combination, the resulting $\mathrm{Fe} / \mathrm{MnO}_{2} @ \mathrm{MnCO}_{3}$ composite achieved more than $90 \%$ degradation of the hormone at near-neutral $\mathrm{pH}(6.7)$ in just 2 min of light irradiation. Given the limit of quantification of the equipment, degradations above $90 \%$ could not be measured reliably (see ESI, Fig. S2†).

Furthermore, this approach was compared to previous works about Fenton-like and photo-Fenton-like degradation of EE2. For instance, Park et al. reported a 90\% degradation of $0.02 \mathrm{ppb}$ of this hormone after $8 \mathrm{~h}$ of Fenton-like reaction with $\mathrm{Ag}$ nanoparticles at $\mathrm{pH} 4,{ }^{43}$ while in our study, a $53 \%$ degradation (0.5 ppm EE2 concentration) value was obtained with our material after $10 \mathrm{~min}$ of Fenton-like reaction at near-neutral $\mathrm{pH}$. Even in a homogeneous photo-Fenton reaction, which is usually considered more efficient than the heterogeneous one, $80 \%$ degradation was reported after $160 \mathrm{~min}$ of UV-visible irradiation at $\mathrm{pH} 33^{44}$ Thus, Fe/ $\mathrm{MnO}_{2} @ \mathrm{MnCO}_{3}$ catalyst is a promising material for the ultrafast degradation of endocrine disruptor chemicals in contaminated water without the need of an acidic $\mathrm{pH}$.

Although the mechanism of the photo-Fenton-like reaction is still not fully understood, it is widely accepted that it involves mainly the generation of hydroxyl radicals (highly reactive species), which are the key players in the oxidation of organic compounds to $\mathrm{CO}_{2}$ and water. ${ }^{45}$ As observed in Fig. 5a, after activation of the $\mathrm{Fe} / \mathrm{MnO}_{2} @ \mathrm{MnCO}_{3}$ catalyst with light energy higher than $\sim 2.2 \mathrm{eV}$, electron $\left(\mathrm{e}^{-}\right)$and hole $\left(\mathrm{h}^{+}\right)$pairs are generated. Then, these photo-generated holes can react with water or hydroxide ions adsorbed on the catalyst surface to produce hydroxyl radicals. In addition, the electrons can contribute to enhancing the reduction of $\mathrm{Fe}^{3+}$ to $\mathrm{Fe}^{2+}$ ions (limiting step), and react with $\mathrm{H}_{2} \mathrm{O}_{2}$ to form additional $\mathrm{HO}^{*}$ radicals. Moreover, $\mathrm{Mn}^{4+}$ and $\mathrm{Mn}^{3+}$ ions help to the recycling of $\mathrm{Fe}^{2+}$ to $\mathrm{Fe}^{3+}$ species by electron transfer. Finally, the reduced $\mathrm{Mn}^{2+}$ ions are oxidized again by the $\mathrm{H}_{2} \mathrm{O}_{2}$ adsorbed on the catalyst surface. ${ }^{46}$

Ohko et al. ${ }^{47}$ studied the photocatalytic degradation mechanism of $17 \beta$-estradiol (E2) over $\mathrm{TiO}_{2}$ photocatalyst. 10ع-17 $\beta$-Dihydroxy-1,4-estradien-3-one and testosterone-like compounds were detected as intermediary products, which were further oxidized to $\mathrm{CO}_{2}$. The whole oxidation pathway was mainly mediated by hydroxyl radicals, starting from the oxidation of the phenol group. Since the molecular configuration of EE2 (steroid structure with a phenol group) is similar to E2 hormone, it can be expected that its degradation mechanism follows the same pathway.
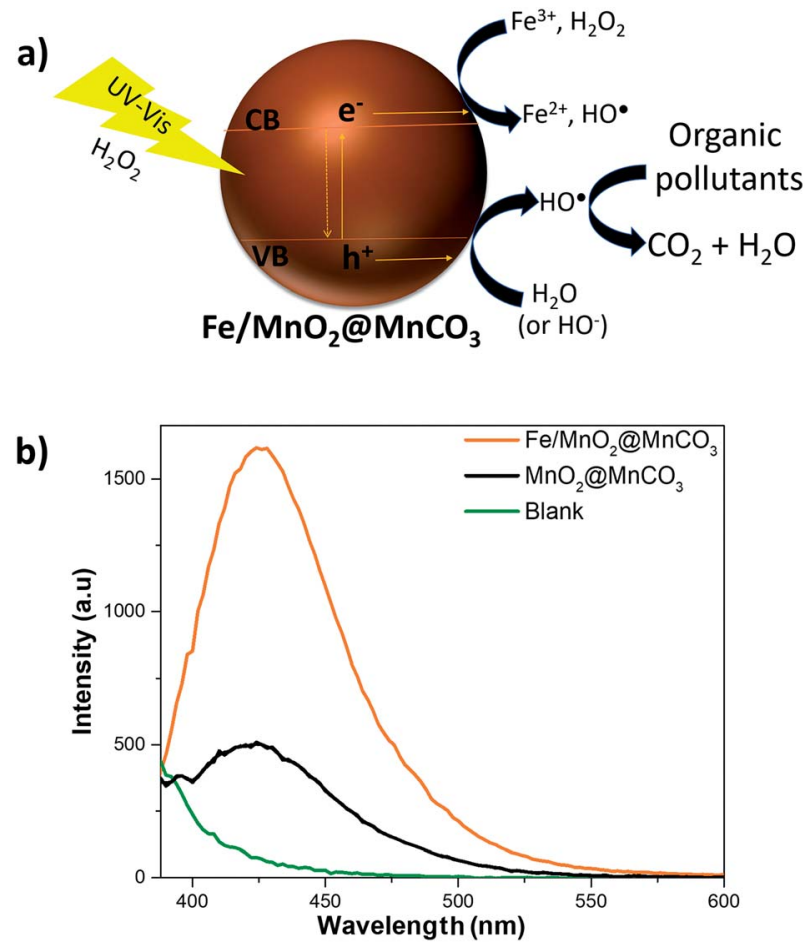

Fig. 5 Insight into the photo-Fenton-like degradation mechanism of EE2. (a) Scheme of the photo-Fenton-like mechanism of Fe/ $\mathrm{MnO}_{2} @ \mathrm{MnCO}_{3}$ and (b) fluorescence spectra of HTA in the presence of $\mathrm{MnO}_{2} \mathrm{Q} \mathrm{MnCO}_{3}$ and $\mathrm{Fe} / \mathrm{MnO}_{2}\left(\mathrm{MnCO}_{3}\right.$ after 10 min of irradiation.

Consequently, to evaluate the radical species produced during the photo-Fenton-like reaction, we examined the formation of hydroxyl radicals using TA to specifically trap these reactive species, and produce 2-hydroxyterephthalic acid (HTA), which exhibits fluorescence emission at $425 \mathrm{~nm}{ }^{48,49}$ The fluorescence spectra corresponding to the formation of HTA in the presence of the catalysts are shown in Fig. 5b. The signal intensity associated with the formation of $\mathrm{HO}^{\circ}$ species was almost 3 times higher in the presence of $\mathrm{Fe} / \mathrm{MnO}_{2} @ \mathrm{MnCO}_{3}$ in comparison with bare $\mathrm{MnO}_{2} @ \mathrm{MnCO}_{3}$. This result clearly confirms that the $\alpha$-FeOOH coating promotes a higher production of hydroxyl radicals on $\mathrm{MnO}_{2} @ \mathrm{MnCO}_{3}$ microparticles, resulting in an enhancement of the degradation of EE2 hormone.

Finally, the reusability of $\mathrm{Fe} / \mathrm{MnO}_{2} @ \mathrm{MnCO}_{3}$ catalyst was studied in the photo-Fenton-like degradation of EE2 after $10 \mathrm{~min}$ of simulated solar irradiation under 3 consecutive cycles. After each test, the sample was recovered by centrifugation and reused with a fresh solution of the hormone. As can be seen in Fig. 6, the catalytic activity decreased by only $6 \%$ between the first and third cycle. This result might be due to a blockage of the active sites by the intermediaries formed during the degradation process that remain adsorbed on the catalyst surface. ${ }^{50,51}$ Based on these results, it seems fair to suggest that this material exhibits a good reusability, which along with its low-cost and up-scalable synthesis, results in a cost-effective catalyst for the efficient degradation of organic pollutants from industry wastewaters. 


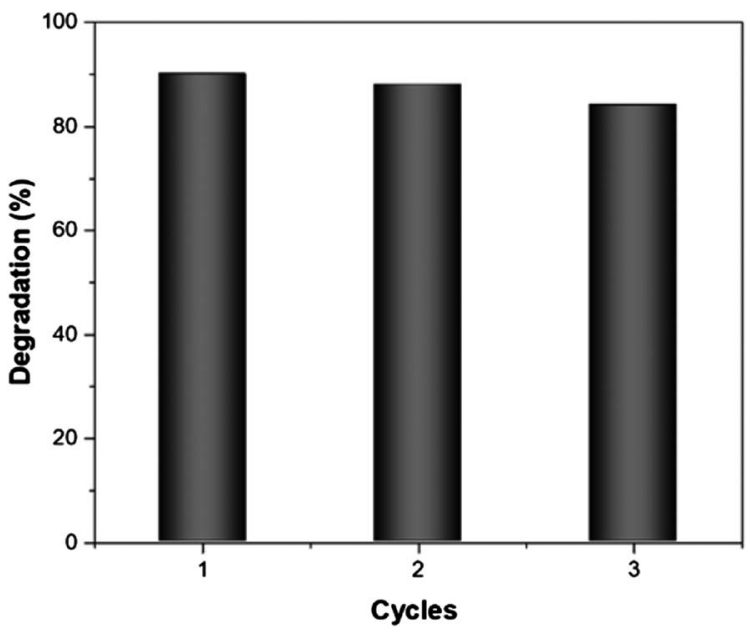

Fig. 6 Reuse of $\mathrm{Fe} / \mathrm{MnO}_{2}\left(\mathrm{aMnCO}_{3}\right.$ catalyst in the photo-Fenton-like degradation of EE2 after 10 min of irradiation. Reaction conditions: EE2 (0.5 ppm), $\mathrm{H}_{2} \mathrm{O}_{2}$ concentration $0.1 \mathrm{M}$. Catalyst loading $0.25 \mathrm{~g} \mathrm{~L}^{-1}$.

\section{Conclusions}

To sum up, we have developed a novel cost-effective and reusable composite based on iron/manganese microspheres, which has demonstrated to be an efficient heterogeneous catalyst for the fast photo-Fenton-like degradation of $17 \alpha$-ethynylestradiol hormone, under simulated solar irradiation. Considering that its synthesis process involves precipitation reaction at room temperature and hydrothermal steps from cheap precursors, this material can be easily obtained at a large scale. The synergy between $\mathrm{FeOOH}$ and $\mathrm{MnO}_{2}$ significantly improves the resulting performance due to a fast activation of $\mathrm{H}_{2} \mathrm{O}_{2}$ and a larger generation of hydroxyl radicals, thus achieving more than $90 \%$ degradation of the hormone within 2 minutes of reaction at near-neutral $\mathrm{pH}$. Moreover, the relatively large size of the resulting composite facilitates the recovery step after each catalytic reaction. Besides this, since the light absorption of $\mathrm{Fe} /$ $\mathrm{MnO}_{2} @ \mathrm{MnCO}_{3}$ catalyst lies in the visible region, this material can be successfully used for the practical application of solar driven Fenton-like systems for the treatment of industrial organic pollutants, without the need of an acidic $\mathrm{pH}$.

\section{Conflicts of interest}

There are no conflicts to declare.

\section{Acknowledgements}

The research leading to these results has received funding from the European Research Council under the European Union's Seventh Framework Program (FP7/20072013)/ERC grant agreement no. 311529 (LT-NRBS) and ERC-2015-PoC/Project ID: 713608 (MICROCLEANERS). D. V. acknowledges financial support provided by the European Commission under Horizon 2020s Marie Skłodowska-Curie Actions COFUND scheme [Grant Agreement No. 712754] and by the Severo Ochoa programme of the Spanish Ministry of Economy and Competitiveness [Grant SEV-2014-0425 (2015-2019)]. S. S. thanks the Spanish MINECO for grants CTQ2015-68879-R (MICRODIA). The authors thank S. Murcia-López and T. Andreu from the Catalan Institute for Energy Research for the structural characterization of the materials. The authors also thank L. Soler for the help with XPS. Authors thank CERCA Programme/Generalitat de Catalunya.

\section{Notes and references}

1 A. J. Ebele, M. Abou-Elwafa Abdallah and S. Harrad, Emerg. Contam., 2017, 3, 1-16.

2 D. Montes-Grajales, G. J. L. Bernardes and J. Olivero-Verbel, Chem. Res. Toxicol., 2016, 29, 150-161.

3 T. Basile, A. Petrella, M. Petrella, G. Boghetich, V. Petruzzelli, S. Colasuonno and D. Petruzzelli, Ind. Eng. Chem. Res., 2011, 50, 8389-8401.

4 L. Soler and S. Sánchez, Nanoscale, 2014, 6, 7175-7182.

5 W. Gao and J. Wang, ACS Nano, 2014, 8, 3170-3180.

6 J. Guzmán, R. Mosteo, M. P. Ormad and J. L. Ovelleiro, J. Agric. Food Chem., 2015, 63, 391-397.

7 C. Sirtori, A. Zapata, I. Oller, W. Gernjak, A. Agüera and S. Malato, Environ. Sci. Technol., 2009, 43, 1185-1191.

8 M. Zhang, Q. Yao, W. Guan, C. Lu and J.-M. Lin, J. Phys. Chem. C, 2014, 118, 10441-10447.

9 W. Luo, L. Zhu, N. Wang, H. Tang, M. Cao and Y. She, Environ. Sci. Technol., 2010, 44, 1786-1791.

10 X. Yang, X. Xu, J. Xu and Y. Han, J. Am. Chem. Soc., 2013, 135, 16058-16061.

11 L. Xu and J. Wang, Environ. Sci. Technol., 2012, 46, 1014510153.

12 J. Katuri, X. Ma, M. M. Stanton and S. Sánchez, Acc. Chem. Res., 2016, 50, 2-11.

13 X. Qian, M. Ren, Y. Zhu, D. Yue, Y. Han, J. Jia and Y. Zhao, Environ. Sci. Technol., 2017, 51, 3993-4000.

14 J. Xu, Y. Li, B. Yuan, C. Shen, M. Fu, H. Cui and W. Sun, Chem. Eng. J., 2016, 291, 174-183.

15 J. He, W. Ma, J. He, J. Zhao and J. C. Yu, Appl. Catal., B, 2002, 39, 211-220.

16 A. Gogoi, M. Navgire, K. C. Sarma and P. Gogoi, Chem. Eng. J., 2017, 311, 153-162.

17 H. Lee, H.-J. Lee, J. Seo, H.-E. Kim, Y. K. Shin, J.-H. Kim and C. Lee, Environ. Sci. Technol., 2016, 50, 8231-8238.

18 E.-J. Kim, D. Oh, C.-S. Lee, J. Gong, J. Kim and Y.-S. Chang, Catal. Today, 2017, 282, 71-76.

19 R. B. Valim, M. C. Santos, M. R. V. Lanza, S. A. S. Machado, F. H. B. Lima and M. L. Calegaro, Electrochim. Acta, 2012, 85, 423-431.

20 M. Safdar, T. D. Minh, N. Kinnunen and J. Jänis, ACS Appl. Mater. Interfaces, 2016, 8, 32624-32629.

21 J. B. Fei, Y. Cui, X. H. Yan, W. Qi, Y. Yang, K. W. Wang, Q. He and J. B. Li, Adv. Mater., 2008, 20, 452-456.

22 J. Tauc and A. Menth, J. Non-Cryst. Solids, 1972, 8, 569-585.

23 R. J. Ramírez, C. A. P. Arellano, A. A. Á. Gallegos, A. E. J. González and S. S. Martínez, J. Photochem. Photobiol., A, 2015, 305, 51-59. 
24 J. Parmar, S. Jang, L. Soler, D.-P. Kim and S. Sánchez, Lab Chip, 2015, 15, 2352-2356.

25 M. C. Biesinger, B. P. Payne, A. P. Grosvenor, L. W. M. Lau, A. R. Gerson and R. S. C. Smart, Appl. Surf. Sci., 2011, 257, 2717-2730.

26 Y. Lv, H. Che, A. Liu, J. Mu, C. Dai, X. Zhang, Y. Bai, G. Wang and Z. Zhang, J. Appl. Electrochem., 2017, 47, 433-444.

27 A. P. Grosvenor, B. A. Kobe, M. C. Biesinger and N. S. McIntyre, Surf. Interface Anal., 2004, 36, 1564-1574.

28 M. Huang, Y. Zhang, F. Li, Z. Wang, Alamusi, N. Hu, Z. Wen and Q. Liu, Sci. Rep., 2014, 4, 4518.

29 S. Zhan, D. Zhu, M. Qiu, H. Yu and Y. Li, RSC Adv., 2015, 5, 29353-29361.

30 H.-Q. Wang, J. Chen, S.-J. Hu, X.-H. Zhang, X.-P. Fan, J. Du, Y.-G. Huang and Q.-Y. Li, RSC Adv., 2015, 5, 72495-72499.

31 C. Baronti, R. Curini, G. D'Ascenzo, A. Di Corcia, A. Gentili and R. Samperi, Environ. Sci. Technol., 2000, 34, 5059-5066.

32 S. Jobling, M. Nolan, C. R. Tyler, G. Brighty and J. P. Sumpter, Environ. Sci. Technol., 1998, 32, 2498-2506.

33 R. Jiang, H.-Y. Zhu, J.-B. Li, F.-Q. Fu, J. Yao, S.-T. Jiang and G.-M. Zeng, Appl. Surf. Sci., 2016, 364, 604-612.

34 K. Villa, X. Domènech, S. Malato, M. I. Maldonado and J. Peral, Int. J. Hydrogen Energy, 2013, 38, 12718-12724.

35 S. Goldstein, D. Aschengrau, Y. Diamant and J. Rabani, Environ. Sci. Technol., 2007, 41, 7486-7490.

36 B. Liu, F. Wu and N. Deng, J. Hazard. Mater., 2003, 98, 311316.

37 S.-H. Do, B. Batchelor, H.-K. Lee and S.-H. Kong, Chemosphere, 2009, 75, 8-12.
38 K. Krumova and G. Cosa, in Singlet Oxygen, 2016, pp. 1-21. 39 J. Zheng, Z. Gao, H. He, S. Yang and C. Sun, Chemosphere, 2016, 150, 40-48.

40 Q. Xia, Z. Jiang, J. Wang and Z. Yao, Catal. Commun., 2017, 100, 57-61.

41 J. Parmar, D. Vilela, E. Pellicer, D. Esqué-de los Ojos, J. Sort and S. Sánchez, Adv. Funct. Mater., 2016, 26, 4152-4161.

42 L. Soler, V. Magdanz, V. M. Fomin, S. Sanchez and O. G. Schmidt, ACS Nano, 2013, 7, 9611-9620.

43 C. M. Park, J. Heo and Y. Yoon, Chemosphere, 2017, 168, 617622.

44 X. Feng, S. Ding, J. Tu, F. Wu and N. Deng, Sci. Total Environ., 2005, 345, 229-237.

45 K. Villa, S. Murcia-López, T. Andreu and J. R. Morante, Catal. Commun., 2015, 58, 200-203.

46 Z. Fang, K. Zhang, J. Liu, J. Fan and Z. Zhao, Water Sci. Eng., 2017, DOI: 10.1016/j.wse.2017.10.005.

47 Y. Ohko, K. Iuchi, C. Niwa, T. Tatsuma, T. Nakashima, T. Iguchi, Y. Kubota and A. Fujishima, Environ. Sci. Technol., 2002, 36, 4175-4181.

48 G. Mendoza-Damián, F. Tzompantzi, A. Mantilla, R. PérezHernández and A. Hernández-Gordillo, Appl. Clay Sci., 2016, 121-122, 127-136.

49 S. Bharathkumar, M. Sakar, R. Vinod K. and S. Balakumar, Phys. Chem. Chem. Phys., 2015, 17, 17745-17754.

50 K. Kaur, R. K. Wanchoo and A. P. Toor, Ind. Eng. Chem. Res., 2015, 54, 3285-3292.

51 H. Chen, W. Liu and Z. Qin, Catal. Sci. Technol., 2017, 7, 2236-2244. 